\title{
Towards near-realtime computation of tsunami inundation as part of the LEXIS project
}

Natalja Rakowsky ${ }^{1}$, Sven Harig ${ }^{1}$, Alexey Androsov ${ }^{1}$, Thierry Goubier ${ }^{2}$, Hannah Neuwirth ${ }^{1,3}$, Lucas Kersten ${ }^{1,4}$

${ }^{1}$ Alfred Wegener Institute, Helmholtz Centre for Polar and Marine Research, Bremerhaven, Germany

${ }^{2}$ CEA List, DSCIN/LCYL, Gif sur Yvette Cedex, France

${ }^{3}$ University of Münster, Germany $\quad{ }^{4}$ University of Göttingen, Germany

EGU General 2020, 4-8 May 2020, online 
EXIs builds an advanced engineering platform at the confluence of HPC, Cloud and Big Data. EX/s" develops infrastructure to enable workflows and demonstrates its abilities through three large-scale socio-economic pilots

- aeronautics

- weather \& climate

- catastrophe alert systems: earthquake \& tsunami

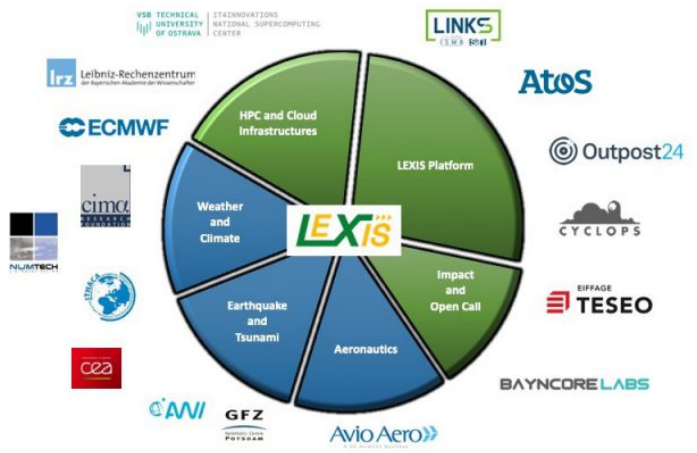




\section{The $\mathbb{E} X \boldsymbol{X}_{\mathrm{s}}$ work flow of the earthquake and tsunami pilot with the} tsunami inundation simulation .

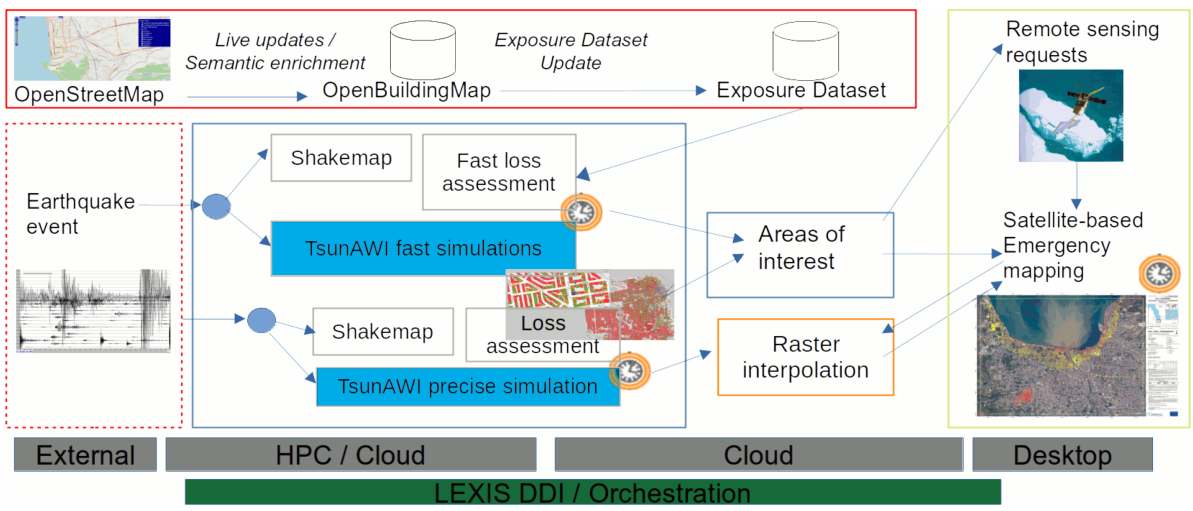




\section{EXX's}

High quality tsunami simulation with inundation is compute intensive. The resolution on land should be $20 \mathrm{~m}$ (Griffin et al. 2015*).

But how coarse can the mesh be for a reasonable estimate?

Grid, zoom to Padang, 20m-5km resolution

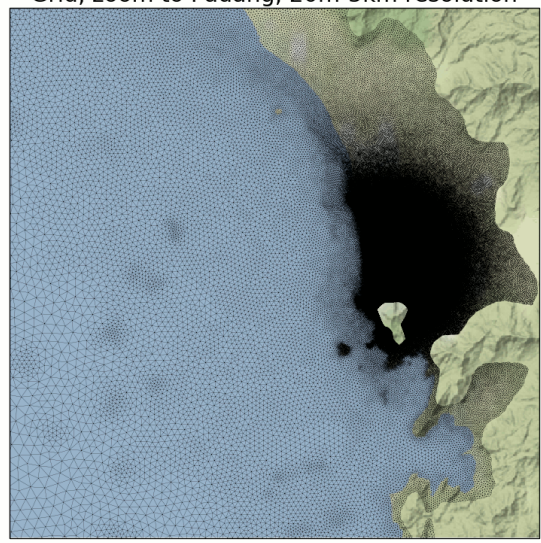

* doi:10.3389/feart.2015.00032 
Simulated inundation on fine mesh

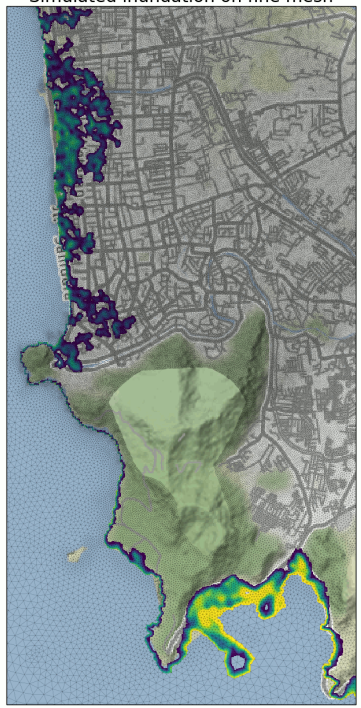

Simulated inundation on coarse mesh

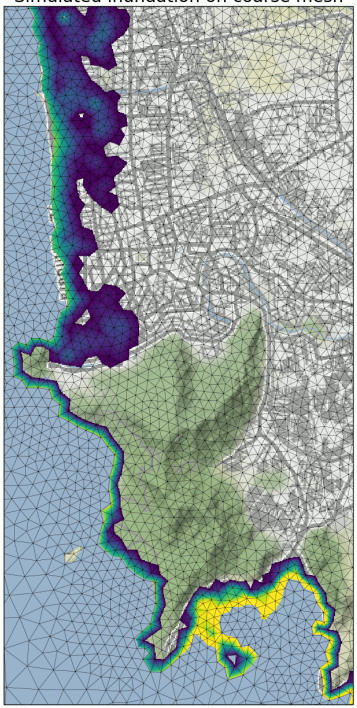

Testing with different 6.0 resolutions: $200 \mathrm{~m}$ is a good choice for a first ${ }_{4.5}$ estimate of the inundation.

$-3.0$

Left: Simulated inundation $[\mathrm{m}]$ of a tsunami caused by a hypothetical earthquake, $\mathrm{Mw}=8.8$, west off Padang, o.o Sumatra, Indonesia. 
Improvements performed in EX/s

- Adapt TsunAWI to the workflow: read quakeML, write raster data or netcdf with the mesh reduced to the inundated area for fast interpolation.

- Profiling. Major bottlenecks: memory bandwidth and NUMA effects vs. load inbalance in TsunAWl's OpenMP.

- Test different mesh resortings. Forsyth's algorithm outperforms the current space filling curve by approx. $10 \%$.

- Planned: Set up automated workflow to tune time step and to remove mesh vertices on land that are not reached by any strong tsunami.

- Planned: Reduce floating point precision double $\rightarrow$ single where possible. 


\begin{tabular}{|c|c|c|c|}
\hline & $\begin{array}{r}\text { Detailed } \\
\text { mesh }\end{array}$ & $\begin{array}{r}\text { Coarse } \\
\text { mesh }\end{array}$ \\
\hline Resolution & $\begin{array}{l}\text { in Padang } \\
\text { in the ocean }\end{array}$ & $\begin{array}{r}20 \mathrm{~m} \\
5,000 \mathrm{~m}\end{array}$ & $\begin{array}{r}200 \mathrm{~m} \\
15,000 \mathrm{~m}\end{array}$ \\
\hline \multicolumn{2}{|c|}{ Number of mesh vertices } & $1,242,653$ & 231,586 \\
\hline \multicolumn{2}{|l|}{ Timestep } & $0.15 \mathrm{~s}$ & $1.5 \mathrm{~s}$ \\
\hline \multirow[t]{3}{*}{$\begin{array}{l}\text { Compute } \\
\text { time for a } \\
2 \mathrm{~h} \text { simul. }\end{array}$} & $\begin{array}{l}\text { salomon.it4i.cz, } \\
24 \text { threads, } \\
\text { 2x Intel Xeon E5-2680v3 }\end{array}$ & 20:40min & $20 \mathrm{~s}$ \\
\hline & $\begin{array}{l}\text { ollie.awi.de, } \\
36 \text { threads, } \\
\text { 2x Intel Xeon E5-2697v4 }\end{array}$ & $15: 45 \min$ & $15 s$ \\
\hline & $\begin{array}{l}\text { lise.hlrn.de, } \\
192 \text { threads w. hyperthreading, } \\
\text { 2x Intel Xeon Platinum } 9242\end{array}$ & $5: 04 \mathrm{~min}$ & $5 s$ \\
\hline
\end{tabular}




\section{Conclusion}

With software optimization, modern hardware, and careful model setup, real-time computation of tsunami inundation becomes feasible.

EXisgives us the chance to focus on the technical aspects. 


\title{
Thanks to all partners in LEXIS!
}

\author{
https://lexis-project.eu
}

This project has received funding from the European Union's Horizon 2020 research and innovation program under grant agreement 825532 